\title{
Optimization criteria for the performance of heat and mass transfer in indirect evaporative cooling systems
}

\author{
YUAN Fang \& CHEN Qun* \\ Key Laboratory for Thermal Science and Power Engineering of Ministry of Education, Department of Engineering Mechanics, Tsinghua \\ University, Beijing 100084, China
}

Received June 4, 2011; accepted October 27, 2011

\begin{abstract}
The wide application of evaporative cooling techniques in which the optimization criteria form the theoretical basis for improving evaporative cooling performance is essential for energy conservation and emission reduction. Based on exergy analysis and the entransy dissipation-based thermal resistance method, this contribution aims to investigate the effects of flow and area distributions in the optimization of the performance of indirect evaporative cooling systems. We first establish the relationships of exergy efficiency, entransy dissipation-based thermal resistance and cooling capacity of a typical indirect cooling system. Using the prescribed inlet parameters, the heat and mass transfer coefficients and the circulating water mass flow rate, we then numerically validate that when the cooling capacity reaches a maximum, the entransy dissipation-based thermal resistance falls to a minimum while the exergy efficiency is not at an extreme value. The result shows that the entransy dissipation-based thermal resistance, not the exergy efficiency, characterizes the heat transfer performance of an evaporative cooling system, which provides a more suitable method for evaluating and analyzing the indirect cooling system.
\end{abstract}

indirect evaporative cooling, optimization criteria, entransy dissipation-based thermal resistance, exergy efficiency

Citation: Yuan F, Chen Q. Optimization criteria for the performance of heat and mass transfer in indirect evaporative cooling systems. Chin Sci Bull, 2012, 57: 687-693, doi: 10.1007/s11434-011-4903-3

Evaporative cooling is a technique in which unsaturated moist air is in contact with water, causing liquid water evaporation resulting in low temperature water or wind. Since the ambient air is clean and low cost, evaporative cooling is the focus of wide interest and applications. Many scientists have undertaken a large amount of research on evaporative cooling systems, mainly on the following three aspects: (1) The analysis of the impact factors on the performance of evaporative cooling systems, such as temperature, humidity and the mass flow rate of moist air $[1,2]$, temperature and the mass flow rate of water [3] and direct/ indirect evaporative cooling with different structures, such as plate types [4,5], tubular types [6,7] and heat pipes [8] etc. (2) The design and optimization of evaporative cooling cycles, including two-stage or three-stage combined direct/ indirect evaporative cooling $[9,10]$ and combined liquid

*Corresponding author (email: chenqun@tsinghua.edu.cn) desiccant dehumidification and evaporative cooling [11]. (3) The performance analysis and optimization theory of evaporative cooling systems, with emphasis on exergy analysis $[12,13]$. In exergy theory, researchers always take exergy efficiency as an assessment index to analyze the exergy loss distribution of all irreversible processes in the system. This involves evaluating the performance of evaporative cooling, and seeking effective ways for improving the performance of evaporative cooling using the criterion that maximum exergy efficiency leads to optimal performance. However, the physical essence of exergy efficiency is the degree of loss of available energy in the process of some form of energy transforming to work. It is not certain whether this can be extended to represent the irreversibility of any two forms of energy so that it is possible to evaluate the transformation of chemical energy and thermal energy in an evaporative cooling system. In fact, in the optimization of heat exchanger groups [14], we have already validated that there is 
no need to use exergy to analyze heat transfer processes that do not involve any thermodynamic cycles.

Moreover, to analyze and optimize the heat transfer process that do not involve any thermodynamic cycles, Guo et al. [15] introduced a physical parameter, entransy, to represent the heat transfer capability of an object or a system, and proposed the minimum entransy dissipation-based thermal resistance principle for heat transfer optimization. This has already been successfully applied to heat transfer processes and apparatuses [16-19] including heat conduction, convective heat transfer, thermal radiation and heat exchangers. Chen et al. subsequently extended the entransy theory to analyze and optimize the mass transfer process [20] and such coupled heat and mass transfer processes as liquid desiccant dehumidification [21] and evaporative cooling [22]. Jiang et al. [23] and Xie et al. [24] proposed a series of theories and methods for optimizing heat and moisture transfer based on entransy theory, which already has some applications in evaporative cooling systems.

From simple heat transfer and mass transfer processes, we have already demonstrated that minimum entransy dissipation-based thermal resistance leads to optimal heat transfer performance. However, by comparison, in a relatively complicated coupled heat and mass transfer process such as an evaporative cooling system, we still need to research the theory to validate the relationship between the minimum entransy dissipation-based thermal resistance and the evaporative cooling performance. Thus, aiming at the problems of flow and area distributions for two typical indirect evaporative cooling systems, this research establishes the internal relationships of exergy efficiency, entransy dissipationbased thermal resistance and the total cooling capacity. After comparing these two relationships, we investigate the physical essence and difference between these two optimization criteria in terms of maximum exergy efficiency and minimum entransy dissipation-based thermal resistance, and finally establish suitable optimization criterion for the evaluation and optimization of an evaporative cooling system.

\section{Evaluation criteria for the heat and mass transfer performance of evaporative cooling systems}

\subsection{Physical model of indirect evaporative cooling systems}

Figure 1 is a schematic of a typical indirect evaporative cooling system. The moist air enters the air-water direct evaporative cooler (2) from the air pre-cooler (1), and comes into direct contact with the circulating water. Because of the water vapor pressure difference between the moist air and the saturated water vapor over the circulating water surface, the water will evaporate and absorb heat to achieve refrigeration. After humidification, the moist air will be discharged by the fan (5). Meanwhile, under the action of the water circulating pump (6), the cooled water

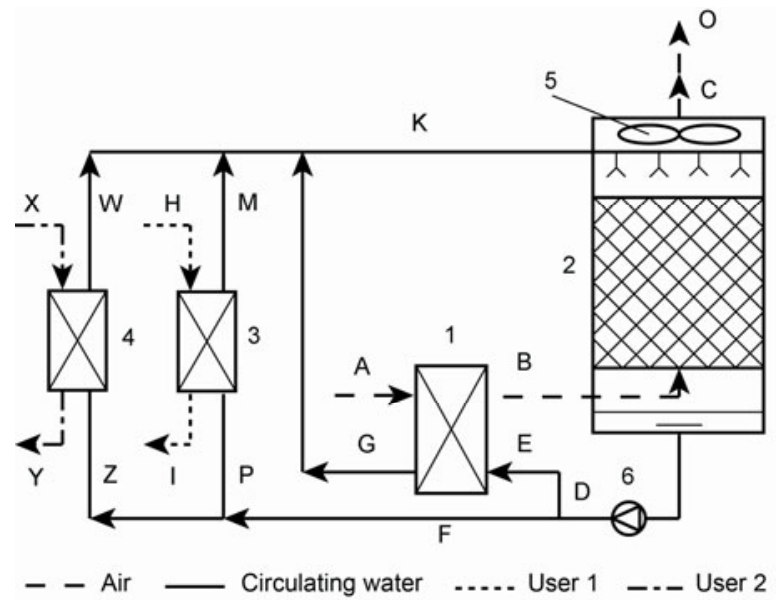

Figure 1 Schematic of a parallel indirect evaporative cooling system.

divides into two branches. One flows into the air pre-cooler (1), to cool the moist air entering into the air-water direct evaporative cooler (2), while the other supplies the two users with a cold source. The circulating water out of the air pre-cooler (1), and the users' heat exchangers (3) and (4), mix together and flow into the direct evaporative cooler (2). The whole system provides cooling capacity, which takes circulating water as a carrier and makes use of the water vapor pressure difference between the moist air and the saturated water vapor on the liquid water surface. The capitals $\mathrm{A}-\mathrm{I}, \mathrm{K}, \mathrm{O}, \mathrm{P}, \mathrm{M}, \mathrm{W}-\mathrm{Z}$, indicate the state positions in the system, where the saturated moist air at the ambient temperature is taken as a benchmark (position $\mathrm{O}$ ). The whole cycle includes three types of irreversible processes: (1) the heat transfer process in the air pre-cooler and the user' heat exchangers; (2) the coupled heat and mass transfer process in the air-water direct evaporative cooler; (3) the mixing process of three circulating water branches.

In Figure $1, m, T, w, Q, c_{p}$ and $\gamma_{0}$ represent mass flow rate, temperature, humidity, cooling capacity, pressure specific heat and evaporation latent heat, respectively. $k_{s} A$ stands for the heat conductance, i.e. the product of the heat transfer coefficient $k_{s}$ and the heat transfer area $A . k_{d}$ is the mass transfer coefficient. The subscripts $1-4, a, w$ and $w a$ represent the air pre-cooler, the air-water direct evaporative cooler, the heat exchanger for user 1 , the heat exchanger for user 2 , the moist air, the circulating water and saturated water vapor, respectively.

The energy conservation equation and the heat transfer equation for the air pre-cooler are

$$
Q_{1}=m_{w, E} c_{p, w}\left(T_{w, G}-T_{w, E}\right)=m_{a, A} c_{p, a}\left(T_{a, A}-T_{a, B}\right)
$$

and

$$
Q_{1}=\left(k_{s} A\right)_{1} \frac{\left(T_{a, A}-T_{w, G}\right)-\left(T_{a, B}-T_{w, E}\right)}{\ln \left(T_{a, A}-T_{w, G}\right)-\ln \left(T_{a, B}-T_{w, E}\right)} .
$$

Similar to the air pre-cooler, the energy conservation 
equation and heat transfer equation of the users' heat exchangers (3) and (4) are written as

$$
\begin{gathered}
Q_{3}=m_{w, H} c_{p, w}\left(T_{w, H}-T_{w, I}\right)=m_{w, M} c_{p, w}\left(T_{w, M}-T_{w, P}\right), \\
Q_{3}=\left(k_{s} A\right)_{3} \frac{\left(T_{w, H}-T_{w, M}\right)-\left(T_{w, I}-T_{w, P}\right)}{\ln \left(T_{w, H}-T_{w, M}\right)-\ln \left(T_{w, I}-T_{w, P}\right)}, \\
Q_{4}=m_{w, X} c_{p, w}\left(T_{w, X}-T_{w, Y}\right)=m_{w, W} c_{p, w}\left(T_{w, W}-T_{w, Z}\right)
\end{gathered}
$$

and

$$
Q_{4}=\left(k_{s} A\right)_{4} \frac{\left(T_{w, X}-T_{w, W}\right)-\left(T_{w, Y}-T_{w, Z}\right)}{\ln \left(T_{w, X}-T_{w, W}\right)-\ln \left(T_{w, Y}-T_{w, Z}\right)} .
$$

For the direct evaporative cooler (2), we need to combine the energy conservation equation, the heat transfer equation and the mass transfer equation as follows for the numerical calculations, because of the coupled heat and mass transfer

$$
\begin{gathered}
m_{w, K} c_{p, w} d T_{w}=k_{s}\left(T_{a}-T_{w}\right) d A+k_{d}\left(w_{a}-w_{w a}\right) d A, \\
m_{a, B} c_{p, a} d T_{a}=k_{s}\left(T_{w}-T_{a}\right) d A,
\end{gathered}
$$

and

$$
\gamma_{0} m_{a, B} d w_{a}=\gamma_{0} k_{d}\left(w_{w a}-w_{a}\right) d A .
$$

Finally, the mixing process of three circulating water branches satisfies the mass and energy conservation equations

$$
m_{w, W}+m_{w, M}=m_{w, K}
$$

and

$$
m_{w, W} T_{w, W}+m_{w, M} T_{w, M}=m_{w, K} T_{w, K} \cdot
$$

With the prescribed inlet states of moist air and user's cooling water, the circulating water mass flow rate and the parameters of each heat exchanger, by simultaneously solving eqs. (1)-(11) we obtain the parameters of each state position in the indirect evaporative cooling system.

\subsection{Exergy analysis for the direct evaporative cooling system}

According to the energy conservation of the coupled heat and mass transfer process

$$
Q_{c}=Q_{3}+Q_{4}=m_{a} c_{p, a}\left(T_{a, C}-T_{a, A}\right)+\gamma_{0}\left(w_{a, C}-w_{a, A}\right),
$$

i.e. the total heat flow rate by evaporation equals the cooling capacity generated by the users' heat exchangers.

From the Second Law of Thermodynamics, the heat and mass transfer process will lose exergy. For water, there is only thermal exergy, while for moist air, because of its two independent parameters, its exergy is the sum of the thermal and moisture exergies. For the indirect evaporative cooling system shown in Figure 1, we can then calculate the exergy loss in the system from the difference between the inlet and outlet exergies. Simultaneously, taking the gas loss of the outlet moist air into consideration, the total exergy loss of the system is

$$
\Delta E_{x}=E_{x, q, H}-E_{x, q, I}+E_{x, q, X}-E_{x, q, Y}+E_{x, q, A}+E_{x, d, A},
$$

where the thermal exergy is

$$
E_{x, q, i}=m_{w, i} c_{p, w}\left[T_{0} \ln \left(\frac{T_{0}}{T_{w, i}}\right)-\left(T_{0}-T_{w, i}\right)\right] i=A, H, I, X, Y,
$$

and the moisture exergy is

$$
\begin{aligned}
& E_{x, d, i} \\
& =m_{a} R_{a} T_{0}\left[\left(1+1.608 w_{a, i}\right) \cdot \ln \frac{1+1.608 w_{0}}{1+1.608 w_{a, i}}+1.608 w \cdot \ln \frac{w_{a, i}}{w_{0}}\right] i \\
& =A,
\end{aligned}
$$

where $E_{x, q, i}, E_{x, d, i}$ and $w_{a, i}$ represent the thermal exergy, the moisture exergy and the humidity of state position $i$, respectively. $R_{a}$ is the gas constant. $T_{0}$ and $w_{0}$ stand for the temperature and humidity of state position $\mathrm{O}$, the exergy value of which appears to be zero. Then, the exergy efficiency standing for the available system energy is

$$
\eta_{e x}=\left(1-\frac{\Delta E_{x}}{E_{x, \text { in }}}\right) \times 100 \%
$$

where, $E_{x, \text { in }}$ represents the total exergy inputted into the system, including the exergy from the inlet air and two users. Its expression is

$$
E_{x, \text { in }}=E_{x, q, H}+E_{x, q, X}+E_{x, q, A}+E_{x, d, A} .
$$

When the inlet parameters of the moist air and the user's cooling water are fixed, $E_{x, \text { in }}$ will remain constant. Solving eqs. (3), (5), (13)-(15) simultaneously, the total system exergy loss is expressed as

$$
\Delta E_{x}=\left\{\begin{array}{l}
m_{w, H} c_{p, w} T_{0} \ln \left(1-\frac{Q_{3}}{m_{w, H} c_{p, w} T_{w, H}}\right)+Q_{3} \\
+m_{w, H} c_{p, w} T_{0} \ln \left(1-\frac{Q_{4}}{m_{w, X} c_{p, w} T_{w, X}}\right)+Q_{4} \\
+E_{x, q, A}+E_{x, d, A}
\end{array}\right\} .
$$

When the total cooling capacity reaches an extreme value, i.e. $d Q_{c}=0$, 


$$
d \eta_{e x}=-\frac{1}{E_{x, \mathrm{in}}} d \Delta E_{x}=-\frac{1}{E_{x, \mathrm{in}}}\left(\frac{T_{0}}{T_{w, Y}}-\frac{T_{0}}{T_{w, I}}\right) d Q_{3} .
$$

It is clear that $d \eta_{e x}$ is relative to $T_{w, I}, T_{w, Y}$ and $T_{0}$, and is obviously not zero, so when $d Q_{c}=0$, the exergy efficiency is not at an extreme value.

\subsection{Entransy analysis for the direct evaporative cooling system}

Chen et al. [22] introduced the concept of moisture entransy to stand for the endothermic capability of a moist air. When taking the saturated moist air at the ambient temperature as a benchmark, water has only thermal entransy, $G_{h}$

$$
G_{w}=G_{h}=\frac{1}{2} m_{w} c_{p, w}\left(T-T_{0}\right)^{2} .
$$

However, the entransy of moist air consists of two parts, thermal entransy and moisture entransy,

$$
G_{a}=G_{h}+G_{d} .
$$

Assuming a linear relationship between humidity $w_{a}$ and its corresponding dew point temperature $T_{a, d p}$, [22], then moisture entransy is expressed as

$$
G_{d}=\frac{1}{2} \gamma_{0} m_{a}\left(T_{a, d p}-T_{0}\right)\left(w_{a}-w_{0}\right),
$$

where, $T_{a, d p}$ is the dew point temperature. Similar to thermal entransy, moisture entransy is defined by the conservation equation of latent heat entransy [22], where, $\rho_{a}$ and $U_{a}$ represent the density and velocity of the moist air,

$$
\begin{aligned}
& \rho_{a} U_{a} \cdot \nabla\left[\frac{1}{2} \gamma_{0}\left(T_{a, d p}-T_{0}\right)\left(w_{a}-w_{0}\right)\right] \\
& =\left\{\begin{array}{l}
\nabla \cdot\left[\rho_{a} k_{d}\left(T_{a}-T_{0}\right) \nabla \gamma_{0}\left(w_{a}-w_{0}\right)\right] \\
-\rho_{a} k_{d} \nabla\left(T_{a}-T_{0}\right) \cdot \nabla \gamma_{0}\left(w_{a}-w_{0}\right) \\
-\left(T_{a}-T_{a, d p}\right) \nabla \cdot\left[\rho_{a} U_{a} \nabla \gamma_{0}\left(w_{a}-w_{0}\right)\right]
\end{array}\right\} .
\end{aligned}
$$

According to the definition of entransy and entransy dissipation of moist air, the total entransy dissipation of the evaporative cooling system shown in Figure 1 is

$$
\Phi_{G}=G_{h, H}-G_{h, I}+G_{h, X}-G_{h, Y}+G_{h, A}+G_{d, A} .
$$

At the benchmark position $O$, the entransy vanishes. We can then define the thermal resistance of the system based on the total entransy dissipation, i.e.

$$
R_{G}=\frac{\Phi_{G}}{Q_{c}^{2}} .
$$

Substituting eqs. (3), (5), (20), (22) and (24) into (25) gives the expression of the entransy dissipation-based thermal resistance for the system,

$$
\begin{aligned}
R_{G}= & {\left[\frac{1}{2} Q_{4}\left(2 T_{w, X}-2 T_{0}-\frac{Q_{4}}{m_{w, X} c_{p, w}}\right)\right.} \\
& \left.+\frac{1}{2} Q_{3}\left(2 T_{w, H}-2 T_{0}-\frac{Q_{3}}{m_{w, H} c_{p, w}}\right)+G_{h, A}+G_{d, A}\right] \times Q_{c}^{-2} .
\end{aligned}
$$

Therefore, when the total cooling capacity reaches an extreme value, i.e. $d Q_{c}=0$,

$$
d R_{G}=\frac{\left(T_{w, I}-T_{w, Y}\right)}{\left(Q_{3}+Q_{4}\right)^{2}} d Q_{3} .
$$

In practical engineering applications, $\left(T_{w, I}-T_{w, Y}\right)<<\left(Q_{3}\right.$ $\left.+Q_{4}\right)^{2}$, and then $\left(T_{w, I}-T_{w, Y}\right) /\left(Q_{3}+Q_{4}\right)^{2} \approx 0$. Therefore, when the cooling capacity reaches an extreme value, the entransy dissipation-based thermal resistance also reaches an extreme value.

To further illustrate the process, we will validate the corresponding relationships of the total cooling capacity, the entransy dissipation-based thermal resistance and the exergy efficiency of the system, by numerical calculation for problems of flow and area distribution in parallel and series indirect evaporative cooling systems. We will then confirm the optimization criterion for the evaporative cooling system.

\section{Performance analysis of flow distribution in a typical indirect evaporative cooling system}

\subsection{The parallel indirect evaporative cooling system}

We consider the parallel indirect evaporative cooling system in Figure 1, in which the air pre-cooler (1) and the users' heat exchangers (3) and (4) are arranged in parallel.

In this case, there exist two kinds of flow distribution:

(i) With the fixed inlet states of moist air and user's cooling water, the circulating water mass flow rate and heat conductance for each heat exchanger, the total cooling capacity, the entransy dissipation-based thermal resistance and the exergy efficiency in the system are all related only to the flow distribution ratio $\varepsilon$. This is defined by the mass flow rate ratio of the water entering the air pre-cooler to the total circulating water, i.e

$$
\varepsilon=\frac{m_{w, E}}{m_{w, D}} .
$$

(ii) With the fixed inlet states of moist air and user's cooling water, the circulating water mass flow rate and heat conductance for each heat exchanger, the total cooling capacity, the entransy dissipation-based thermal resistance and the exergy efficiency in the system are all related only to the flow distribution ratio $\xi$. This is defined by the mass flow rate ratio of the water entering the user's heat exchanger (3) to the circulating water supplied for the users, i.e. 


$$
\xi=\frac{m_{w, P}}{m_{w, F}}
$$

If the flow distribution ratio, $\xi$, is fixed, the system has only one variable, i.e. the flow distribution $\varepsilon$. When the inlet temperature, humidity and mass flow rate of the moist air, are $305 \mathrm{~K}, 0.008 \mathrm{~kg} / \mathrm{kg}$ and $1.9 \mathrm{~kg} / \mathrm{s}$, respectively, the user's cooling water flows into system at $305 \mathrm{~K}$ and $1 \mathrm{~kg} / \mathrm{s}$ for user 1 , and $301 \mathrm{~K}$ and $3 \mathrm{~kg} / \mathrm{s}$ for user 2, the total circulating water mass flow rate is $2 \mathrm{~kg} / \mathrm{s}(\xi=0.5)$. The heat conductances for the air pre-cooler, direct evaporative cooler, and users' heat exchangers (3) and (4) are 4000, 8000, 8000 and $6000 \mathrm{~W} / \mathrm{K}$, respectively, and the Lewis number reaches 1 . Figure 2 shows the variation of the total cooling capacity, entransy dissipation-based thermal resistance and exergy efficiency versus the flow distribution ratio $\varepsilon$. The vertical coordinates are normalized by their individual maximum values for ease of comparison. Accompanying the increment of $\varepsilon$, both the total cooling capacity and exergy efficiency increase first and then decrease, while conversely the entransy dissipationbased thermal resistance decreases first and then increases. Under this condition, when $\varepsilon$ reaches 0.14 , both the minimum entransy dissipation-based thermal resistance and the maximum exergy efficiency correspond to the maximum total cooling capacity.

When the system flow distribution $\varepsilon$ is fixed, and we change $\xi$, we keep the inlet parameters of moist air and user's cooling water and heat conductance of four heat exchangers the same, and assume $\varepsilon=0.2$. In this situation, the variation trend of the total cooling capacity, entransy dissipationbased thermal resistance and exergy efficiency, again normalized by their individual maximum values, versus the flow distribution ratio $\xi$ are shown in Figure 3. The results show that as $\xi$ increases, both the total cooling capacity and exergy efficiency increase first and then decrease, while the entransy dissipation-based thermal resistance has the opposite

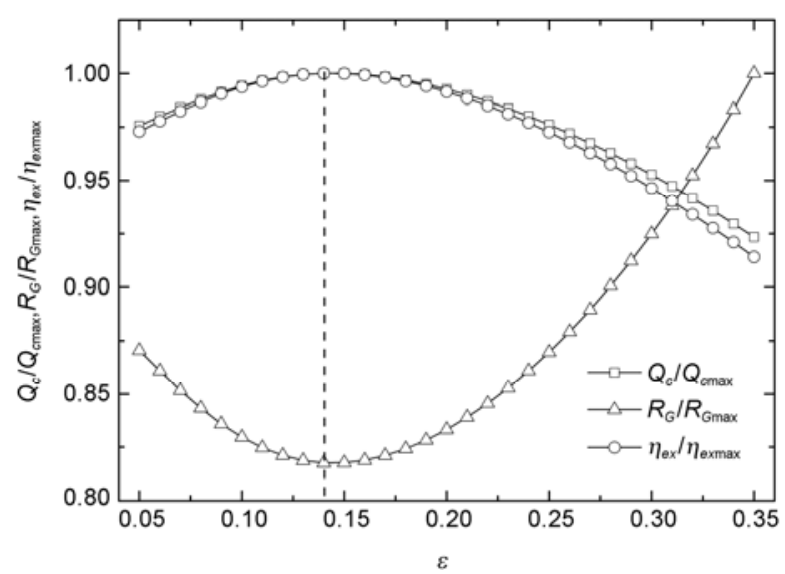

Figure 2 The total cooling capacity, entransy dissipation-based thermal resistance and exergy efficiency versus flow distribution ratio $\varepsilon$ in the parallel indirect evaporative cooling system.

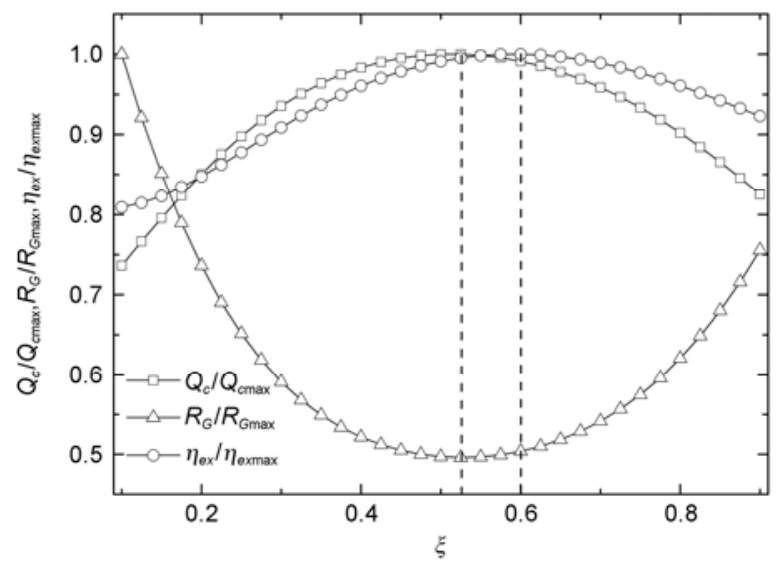

Figure 3 The total cooling capacity, entransy dissipation-based thermal resistance and exergy efficiency versus flow distribution ratio $\xi$ in the parallel indirect evaporative cooling system.

trend. When $\xi$ reaches 0.525 , the minimum entransy dissipation-based thermal resistance corresponds to the maximum achievable total cooling capacity, with the maximum exergy efficiency achieved at $\xi=0.6$. This demonstrates that only the entransy dissipation-based thermal resistance can affect the cooling performance of this indirect evaporative cooling system, i.e. the lower the entransy dissipationbased thermal resistance the better the evaporative cooling performance.

\subsection{The series indirect evaporative cooling system}

We now consider the series indirect evaporative cooling system in Figure 4, where the air pre-cooler (1) and users' heat exchangers (3) and (4) are arranged in series. Likewise, with the fixed inlet states of the moist air and user's cooling

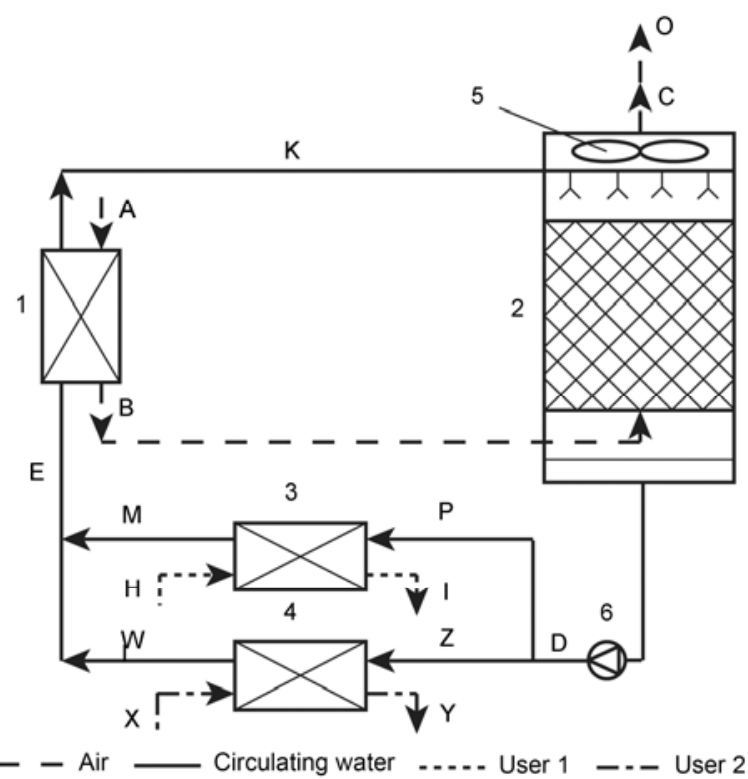

Figure 4 Schematic of a series indirect evaporative cooling system. 
water, the circulating water mass flow rate and heat conductance for each heat exchanger, the total cooling capacity for the indirect evaporative cooling system varies with different flow distribution ratio $\xi$.

In this cycle, the mathematical relationships of the total cooling capacity $Q_{c}$, exergy efficiency $\eta_{e x}$ and entransy dissipation-based thermal resistance $R_{G}$ with the flow distribution ratio $\xi$, will change because of the change in the cycle arrangement, but they are still only related to $\xi$.

Under the same condition in section 2.1, the total cooling capacity, entransy dissipation-based thermal resistance and exergy efficiency versus the flow distribution ratio $\xi$ are shown in Figure 5. Increasing $\xi$ will first increase and then decrease the total cooling capacity and exergy efficiency, while the entransy dissipation-based thermal resistance will first decrease and then increase. The total cooling capacity and the entransy dissipation-based thermal resistance reaches an extreme value at $\xi=0.5$, while exergy efficiency is achieved at $\xi=0.575$. This still shows that the entransy dissipation-based thermal resistance is more suitable for evaluating the cooling performance of an indirect evaporative cooling system.

\section{Performance analysis of area distribution in typical indirect evaporative cooling systems}

\subsection{The parallel indirect evaporative cooling system}

We again consider the parallel indirect evaporative cooling system schematic shown in Figure 1. Because the heat conductance for the heat exchanger, consisting of the heat transfer area and heat transfer coefficient, is limited by the investment costs, it makes sense to consider it as a constraint on the sum of the heat conductance of the heat exchangers (3) and (4), i.e. $k_{S} A=\left(k_{S} A\right)_{3}+\left(k_{S} A\right)_{4}=$ const. With the fixed inlet states of the moist air and user's cooling water, and of the circulating water mass flow rate and flow distri-

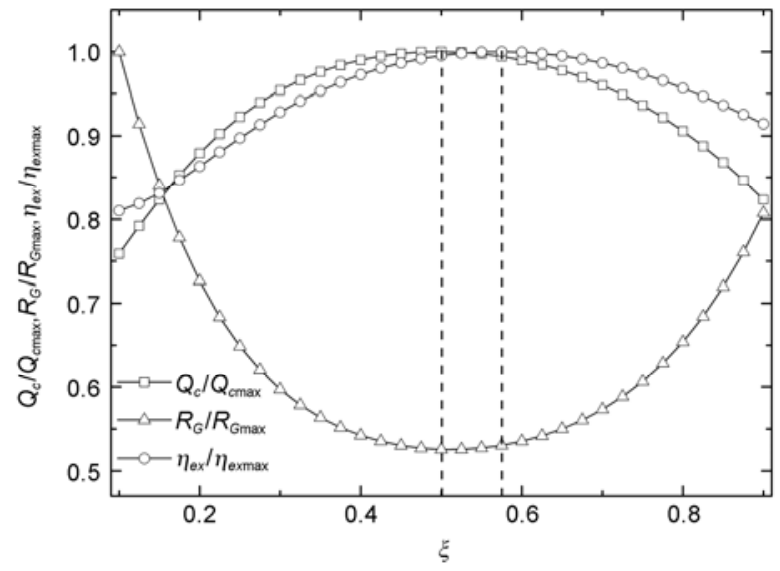

Figure 5 The total cooling capacity, entransy dissipation-based thermal resistance and exergy efficiency versus flow distribution ratio $\xi$ in the series indirect evaporative cooling system. bution ratio $\varepsilon$ and $\xi$, the change area distribution ratio $\alpha$ will then achieve the maximum total cooling capacity for the system. We define

$$
\alpha=\frac{\left(k_{s} A\right)_{3}}{k_{s} A} .
$$

When the inlet temperature, humidity and mass flow rate of the moist air are $305 \mathrm{~K}, 0.008 \mathrm{~kg} / \mathrm{kg}$ and $1.9 \mathrm{~kg} / \mathrm{s}$, respectively, the user's cooling water flows into the system at $305 \mathrm{~K}$ and $1 \mathrm{~kg} / \mathrm{s}$ for user 1 and $301 \mathrm{~K}$ and $3 \mathrm{~kg} / \mathrm{s}$ for user 2, the total circulating water mass flow rate is $2 \mathrm{~kg} / \mathrm{s}(\varepsilon=0.2, \xi=0.5)$, the heat conductances of the air pre-cooler and direct evaporative cooler are 4000 and $8000 \mathrm{~W} / \mathrm{K}$, respectively, the total heat conductance for the two users is $15000 \mathrm{~W} / \mathrm{K}$, and the Lewis number is 1. Figure 6 shows the variation curves for the total cooling capacity, entransy dissipation-based thermal resistance and exergy efficiency versus the area distribution ratio $\alpha$. With the increasing $\alpha$, both the total cooling capacity and exergy efficiency increase first and then decrease, while the entransy dissipation-based thermal resistance is the converse. Under this condition, when $\alpha$ reaches 0.55 , the minimum entransy dissipation-based thermal resistance corresponds to the maximum achievable total cooling capacity while the maximum exergy efficiency is at $\alpha=0.6$.

\subsection{The series indirect evaporative cooling system}

To establish the relationships between the total cooling capacity, exergy efficiency and entransy dissipation-based thermal resistance, with the area distribution ratio $\alpha$ for the series indirect evaporative cooling system, we apply the same known parameters as in section 3.1, but with reduced inlet temperature for the user's cooling water for heat exchanger (4) at $297 \mathrm{~K}$. The variation trend of the total cooling capacity, entransy dissipation-based thermal resistance and exergy efficiency versus the area distribution ratio $\alpha$ are shown in Figure 7. Increasing $\alpha$ will first increase and then

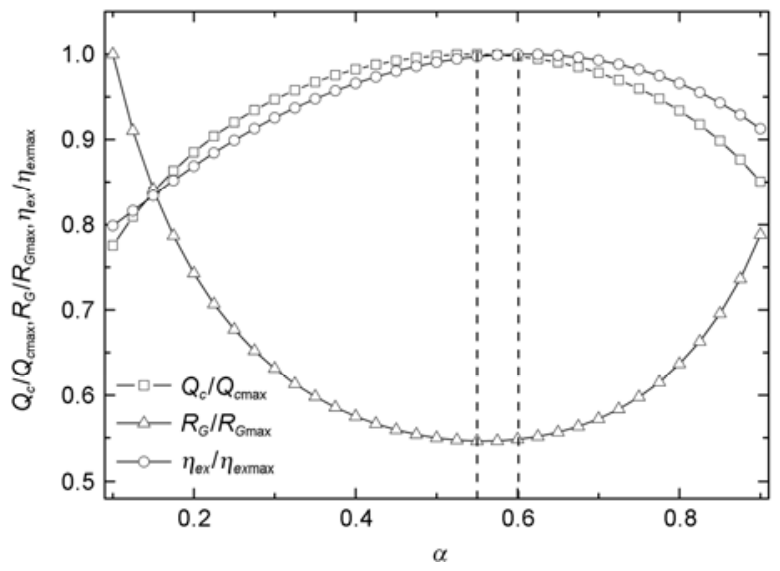

Figure 6 The total cooling capacity, entransy dissipation-based thermal resistance and exergy efficiency versus area distribution ratio $\alpha$ in the parallel indirect evaporative cooling system. 


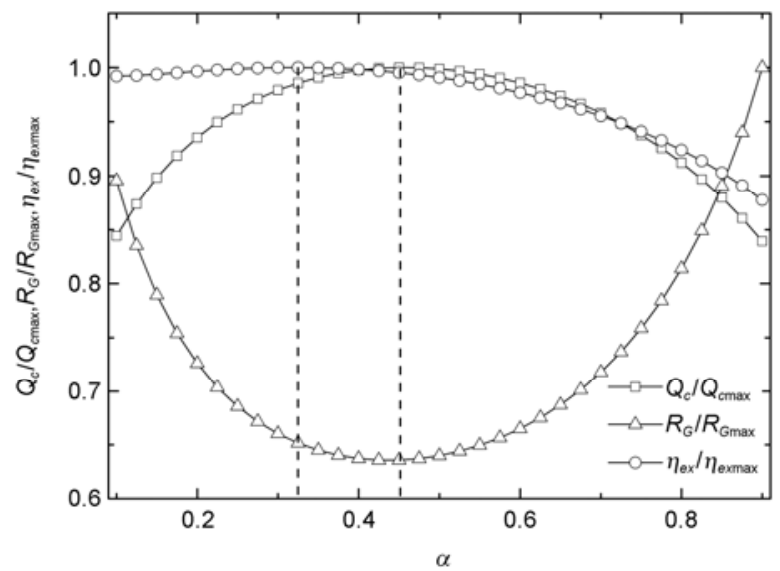

Figure 7 The total cooling capacity, entransy dissipation-based thermal resistance and exergy efficiency versus area distribution ratio $\alpha$ in the series indirect evaporative cooling system.

decrease the total cooling capacity and exergy efficiency, while the entransy dissipation-based thermal resistance, will first decrease and then increase. The total cooling capacity and the entransy dissipation-based thermal resistance reach the extreme value at $\alpha=0.45$, while the exergy efficiency is achieved at $\alpha=0.325$.

\section{Conclusions}

This paper studies the applicability of the two optimization criteria of the maximum exergy efficiency method and the minimum entransy dissipation-based thermal resistance method in flow and area distribution optimizations for evaporative cooling systems. After constructing the relationship of the cooling capacity with exergy efficiency and entransy dissipation-based thermal resistance in the system, we validate the conclusions of the theoretical analysis by numerical calculation and conclude that in performance optimization of flow and area distributions for the parallel and series indirect evaporative cooling systems, when the entransy dissipation-based thermal resistance reaches a minimum the cooling capacity of the system reaches a maximum, i.e. the optimal evaporative cooling performance, but the exergy efficiency does not achieve its maximum value at the same time.

In conclusion, applying entransy analysis and the minimum entransy dissipation-based thermal resistance method to evaluate and optimize the evaporative cooling performance of the systems, without involving any thermodynamic cycles is very achievable.

The work was supported by the National Natural Science Foundation of China (51006060).
1 Tulsidasani T R, Sawhney R L, Singh S P, et al. Recent research on an indirect evaporative cooler (IEC), Part I: Optimization of the cop. Int J Energy Res, 1997, 21: 1099-1108

2 Muangnoi T, Asvapoositkul W, Wongwises S. Effects of inlet relative humidity and inlet temperature on the performance of counterflow wet cooling tower based on exergy analysis. Energy Convers Manage, 2008, 49: 2795-2800

3 Lemouari M, Boumaza M, Kaabi A. Experimental analysis of heat and mass transfer phenomena in a direct contact evaporative cooling tower. Energy Convers Manage, 2009, 50: 1610-1617

4 Scofield C M, Deschamps N H. Indirect evaporative cooling using plate type heat exchangers. ASHRAE Transactions, 1984, 90: 148-153

$5 \mathrm{Wu} \mathrm{H}$, Yellott J I. Indirect evaporative cooling system for residences in hot and arid climates. ASHRAE Trans, 1987, 93: 1252-1260

6 Singh S P, Tulsidasani T R, Sawhney R L, et al. Recent research on an indirect evaporative cooler, Part VI: Evolution of design pattern for indirect evaporative cooler. Int J Energy Res, 1999, 23: 557-561

7 Watt J R. Nationwide evaporative cooling is here. ASHRAE Transactions, 1987, 93: 1237-1251

8 Scofield C M. The heat pipe used for dry evaporative cooling. ASHRAE Trans, 1986, 92: 371-381

9 Anderson W M. Three-stage evaporative air conditioning versus conventional mechanical refrigeration. ASHRAE Trans, 1986, 92: 358-370

10 Al-Juwayhel F, El-Dessouky H, Ettouney H, et al. Experimental evaluation of one, two, and three stage evaporative cooling systems. Heat Transf Eng, 2004, 25: 72-86

11 Dai Y J, Wang R Z, Zhang H F, et al. Use of liquid desiccant cooling to improve the performance of vapor compression air conditioning. Appl Therm Eng, 2001, 21: 1185-1202

12 Muangnoi T, Asvapoositkul W, Wongwises S. An exergy analysis on the performance of a counterflow wet cooling tower. Appl Therm Eng, 2007, 27: 910-917

13 Ren C Q, Li N P, Tang G F. Principles of exergy analysis in HVAC and evaluation of evaporative cooling schemes. Build Environ, 2002, 37: 1045-1055

14 Chen Q, Wu J, Wang M R, et al. A comparison of optimization theories for energy conservation in heat exchanger groups. Chin Sci Bull, 2011, 56: 449-454

15 Guo Z Y, Zhu H Y, Liang X G. Entransy-A physical quantity describing heat transfer ability. Int J Heat Mass Transf, 2007, 50: 2545-2556

16 Xia S J, Chen L G, Sun F R. Entransy dissipation minimization for liquid-solid phase change processes. Sci China Technol Sci, 2010, 53: 960-968

17 Chen Q, Ren J, Meng J A. Field synergy equation for turbulent heat transfer and its application. Int J Heat Mass Transf, 2007, 50: 5334-5339

18 Cheng X T, Liang X G. Entransy flux of thermal radiation and its application to enclosures with opaque surfaces. Int J Heat Mass Transf, 2011, 54: 269-278

19 Li X F, Guo J F, Xu M T, et al. Entransy dissipation minimization for optimization of heat exchanger design. Chin Sci Bull, 2011, 56: 869-873

20 Chen Q, Ren J X, Guo Z Y. The extremum principle of mass entransy dissipation and its application to decontamination ventilation designs in space station cabins. Chin Sci Bull, 2009, 54: 2862-2870

21 Chen L, Chen Q, Li Z, et al. Moisture transfer resistance method for liquid desiccant dehumidification analysis and optimization. Chin Sci Bull, 2010, 55: 1445-1453

22 Chen Q, Yang K D, Wang M R, et al. A new approach to analysis and optimization of evaporative cooling system I: Theory. Energy, 2010, 35: 2448-2454

23 Jiang Y, Xie X Y, Liu X H. Thermological principle of moist air heat and moisture conversion processes (in Chinese). HV\&AC, 2011, 41: 51-64

24 Xie X Y, Jiang Y. Thermological analysis of chilled water by evaporative cooling processes (in Chinese). HV\&AC, 2011, 41: 65-76

Open Access This article is distributed under the terms of the Creative Commons Attribution License which permits any use, distribution, and reproduction in any medium, provided the original author(s) and source are credited. 